\title{
MÁSCARAS: MULTIDÃO: DISPERSÃO: DOIS PONTOS
}

\section{MASKS: MULTITUDE: DISPERSION: COLON}

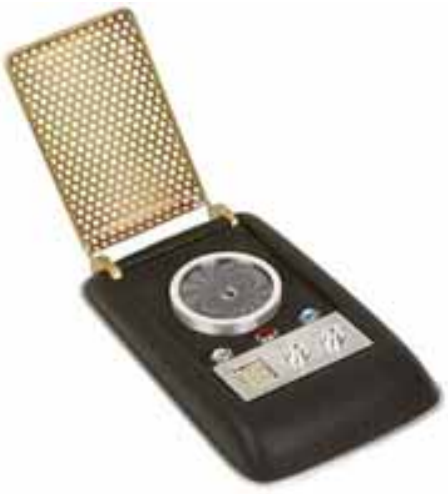

\section{Elenise Cristina Pires de Andrade Érica Speglich}

Dois pontos, apresentação.

Três pontos, reticências.

Um ponto, final? De exclamação? De interrogação?

Infinitos pontos:... ?!.

Infinito como as estrelas?

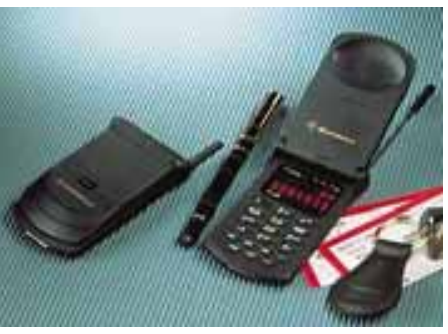

Lembra do Capitão Kirk chamando sua nave em Star Trek pelo comunicador? Isso foi feito na década de 60, de onde veio a inspiração para o StarTac!

Fonte: http://ventocontra.blogspot.com/2007_06_01_archive.html

Alô, alô marciano.

Aqui quem fala é da Terra!

Pra variar estamos em guerra... ${ }^{1}$

\section{Zieralderribume}

Costumava ser mais fácil: fechar as fronteiras, montar os bloqueios de estrada, parar os trens, cortar as linhas telefônicas e então reprimir seu povo com impunidade. Foi isto o que os militares fizeram na antiga Birmânia quando esmagaram um levante pró-democracia em 1988.Na semana passada, quando os generais começaram a atacar os monges budistas e seus simpatizantes nas ruas de Mianmar, eles descobriram que o mundo tinha mudado. As pessoas estavam assistindo. A junta se viu face a face com uma revolução na tecnologia da resistência, na qual um exército guerrilheiro de cidadãos repórteres estava transmitindo vídeos, fotos e notícias pela Internet enquanto os eventos se desenrolavam. As imagens chegaram às telas de televisão e aos jornais, e o mundo foi inundado de cenas de dezenas de milhares de monges nas ruas e do caos e violência enquanto a junta reprimia o maior levante popular em duas décadas. A velha tecnologia de armas e cassetetes foi superada pelo imediatismo da comunicação eletrônica de uma forma que o mundo nunca viu. (...)"Hoje, todo cidadão é um correspondente de guerra", disse Phillip Knightley, autor de "The First Casualty" (a primeira baixa), uma história do jornalismo de guerra que começa com as cartas enviadas por soldados na Criméia, nos anos 1850, à "guerra na sala de estar" no Vietnã nos anos 70, quando pessoas puderam assistir uma guerra pela televisão pela primeira vez."Os celulares com vídeo com capacidade de transmissão possibilitaram a qualquer um noticiar uma guerra", ele escreveu em uma entrevista por e-mail. "Basta apenas estar lá".

\footnotetext{
${ }^{1}$ Versos da canção Alô, alô, marciano, de Rita Lee e Roberto de Carvalho.

${ }^{2}$ Reportagem de 04/10/2007 intitulada Mianmar se vê face a face com uma revolução tecnológica de autoria de Seth Mydans em Bancoc, Tailândia. Tradução: George El Khouri Andolfato.
} 

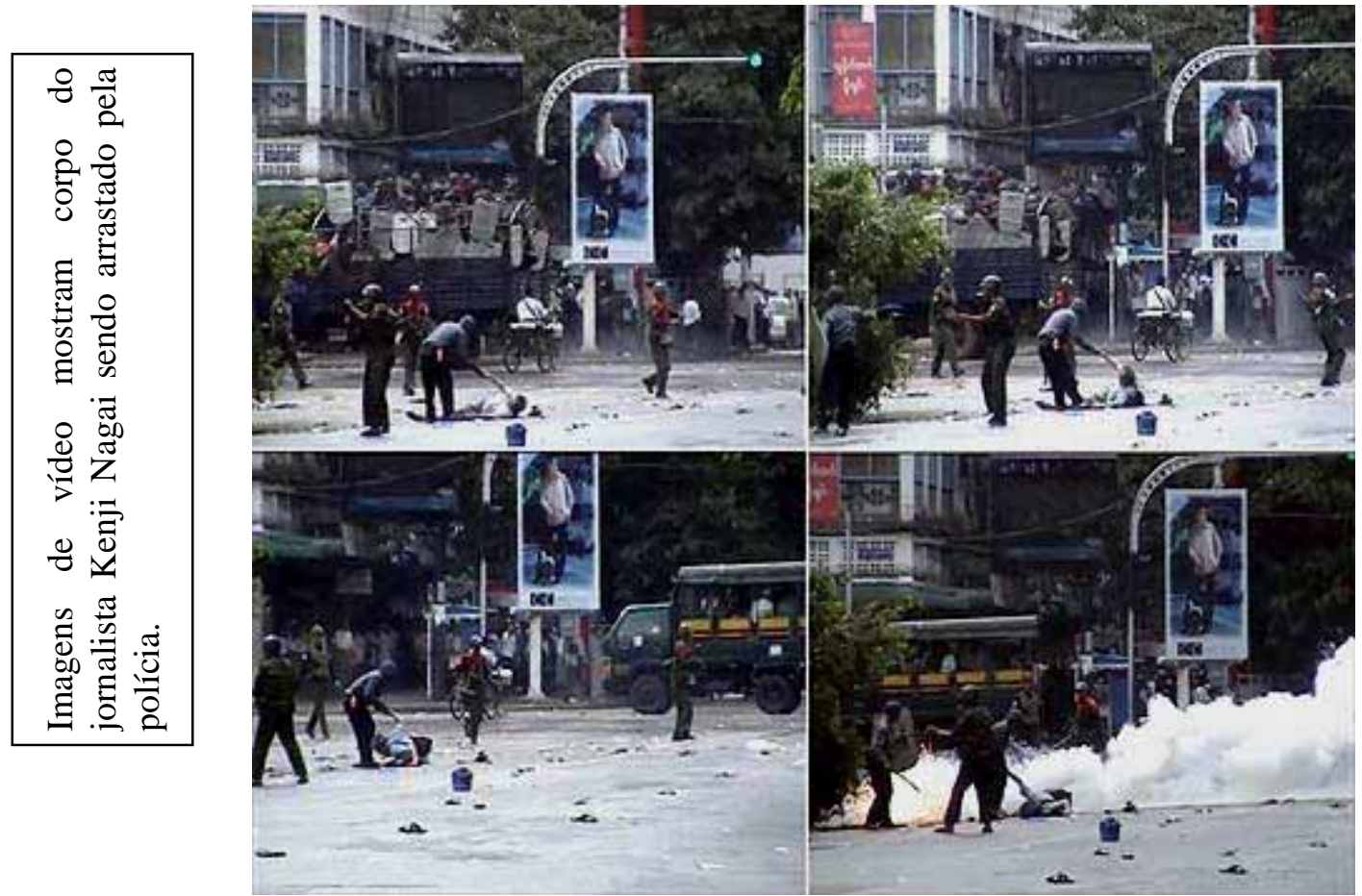

Pra variar continuaríamos em guerra? Imagens, aglomerações, dispersões, dissoluções de continuidades, contigências que nos assombram. Sombras. Sobras. "Basta apenas estar lá”, nos aponta Phillip Knightley. Onde seria lá? Bastaria ser lá? Apenas estar? Star Trek, StarTac. Produções cinematográficas por entre estrelas e transportadores de moléculas, de viagens, de vozes, de protestos, desmaterializando o concreto, os cacetetes, as telas de cinema. Vazios que viajam. Resíduos em dissoluções de cinema nos movimentos de fabulação de mundos, sem finalidade, sem objetivo, sem a necessidade de se referir ao concreto. Despretensão do senso e da utilidade, da busca pela equivalência da representação, ficando “apenas” com o desejo e a força de produção.

Queremos, aqui, potencializar o indizível nos espaços entre os 24 frames por segundo no movimento que é paralisação. Ou na paralisação que se movimenta? Dispersão e multidão de pixels, esquecimentos, memórias, idéias, conhecimentos, sensações e convidar uma provocação de Paolo Virno (2003) que nos apresenta um entendimento considerado potente para nós - o conceito de multidão em pluralidades - ao invés de investirmos no conceito de "povo". Virno ainda propõe o povo apresentaria uma disposição centrípeta 


\section{Área Temática: Educação Visual, Linguagens Visuais e Arte}

convergente para um desejo geral, enquanto que a multidão aboliria a unidade política recusando a obediência, inclinando-se em direção a formas democráticas não-representativas.

\section{Pensamentosescritaspesquisas que se} esparramam extrapolando o que havíamos pensado anteriormente num movimento esquizofrênico a desafiar as classificações. Inspiração em multidões. Espalhamentos, aglomerações, imagens, dois pontos em conectivos que não sintetizam, não significam, não equivalem - essa a vontade desse texto, das imagens, das palavras, das idéias. Desejo maquínico de potência de vida e não de explicação.
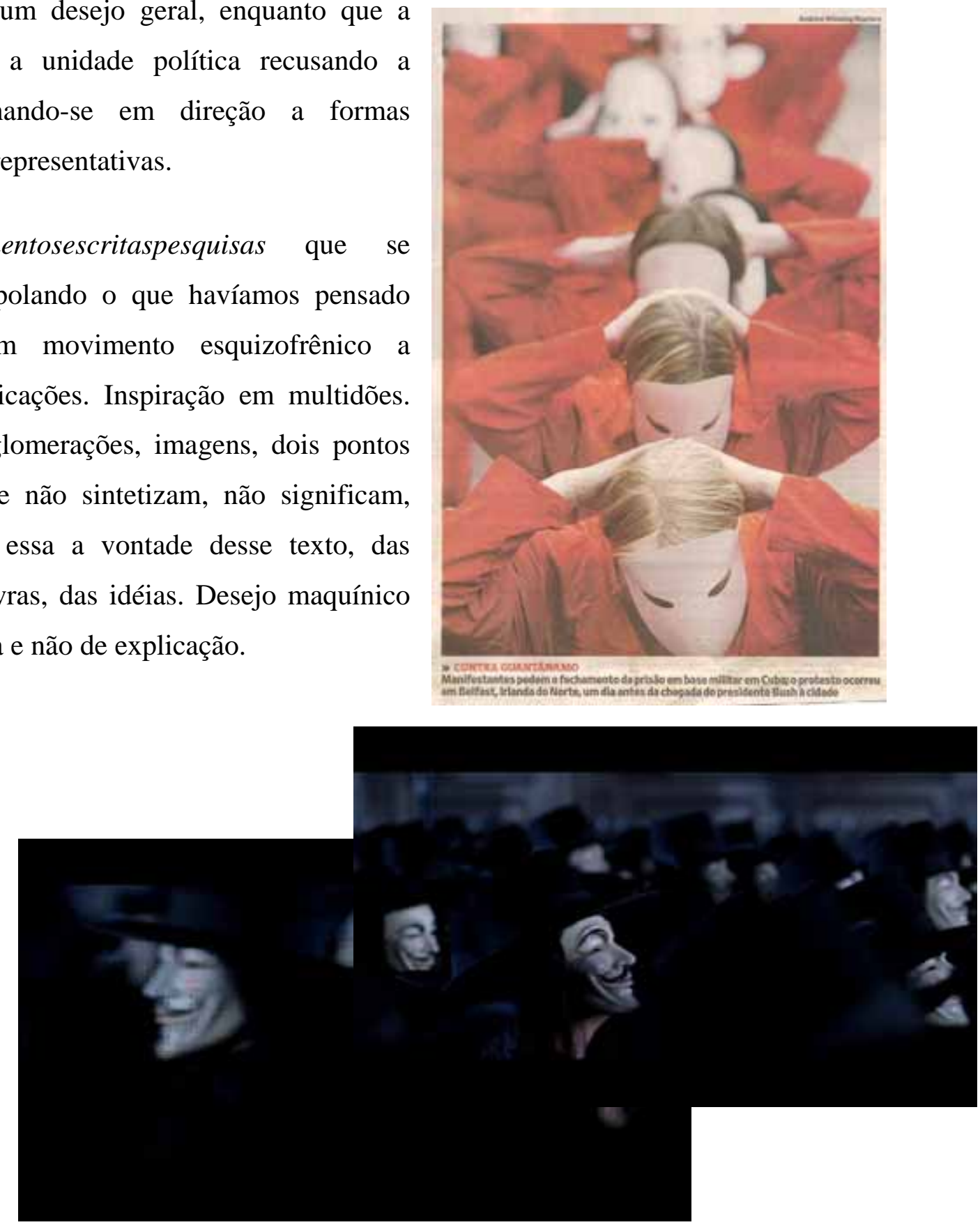

Trazer e levar rachaduras de cinema, HQs, movimentos, concretudes e resistências. Fugir das negatividades e fixações que tantos “povos morais” pregam e disseminá-las em multiplicação criativa. Máscaras: multidão: dispersão: dois pontos ao mundo fabulado pelo cinema que o invade para aglomerarmos em imagens que se alastram pelos jornais da contemporaneidade em uma hibridização caoticamente criadora.

Aglomeração que não busca a síntese, mas a produção de multiplicidades que agem, que desejam. Proliferação de barulhos, ruídos, movimentos afásicos, o acontecimento 
como expressão imediata de uma resistência política maquínica. Resistência e(m) perturbações inspiradas em Maurizio Lazzarato (1994).

Mascarados com trajes vermelhos em Belfast ${ }^{3}$. Mascarados de preto em Londres ${ }^{4}$. Movimentos $^{5}$ que não produziriam nenhuma forma de luta, organização, discurso ou formas de subjetivação que seja imediatamente funcional à reivindicação e seus objetivos. Essa flexibilidade, plasticidade e reversibilidade das formas de subjetivação certamente constituíram a força mais extraordinária desse movimento [dos imigrantes], mas talvez também sua fraqueza (LAZZARATO, 1994).

Deixarmo-nos tocar pelas forças que o autor italiano destaca para os movimentos da contemporaneidade: flexibilidade, plasticidade e reversibilidade em (des)encontros percorridos às peripécias de Gilles Deleuze (2007, p. 102-3) quando se encanta pela obra de Francis Bacon e o movimento. Inúmeras (im)possibilidades na potência da nitidez provocada pelas máscaras em um funcionamento de limpeza de uma figuração pré-existente. Apostas em potência no devir das multiplicitudes das máscaras. Limpeza e nitidez para fugir do figurativo - limpar, varrer e amarrotar (DELEUZE, 2007, p.103) para provocar um outro entendimento de movimento e luta - Movimento é a indefinição e a imperfeição de toda política. Sempre deixa um resíduo (AGAMBEN, 2005).

Convidar a invasão dos funcionamentos maquínicos - máquina que não é figurativa, narrativa. Propomos maquinações em criações de rotas de fuga numa produção de conhecimento, de pensamentos nas dispersões do entre. Não pretendemos atrelar as imagens a com-textos de coerência, significados, representações. Não queremos pensar o cinema como representação do mundo, mas pensar com o cinema que é o próprio mundo se fazendo, se inventando. Queremos destituir as imagens de bom senso e de classificações como propõe o modelo platônico de mundo e apostar na proliferação e produção de sentidos atribuídos pelo non sense. Abolir a comparação do mesmo e desejar o maquínico na produção do diferentemente diferente, que se desfaz e assume o fora, a diferença pura atravessante da

\footnotetext{
${ }^{3}$ Jornal Folha de São Paulo, 16 de junho de 2008.

${ }^{4}$ Imagem da produção cinematográfica "V de Vingança", dirigida por James McTeigue, lançada em 2006.

${ }^{5}$ A discussão do pensador italiano centra-se, inicialmente, nos movimentos sociais de reivindicação de direitos promovidos pelos imigrantes árabes em território francês. Além disso, aponta algumas categorias que começam a movimentar a análise política assim como as próprias reivindicações dos grupos sociais: "integração" e "exclusão", intensificando as discussões a respeito do espaço num certo "detrimento hierárquico" às questões salariais, tão em voga na década de 1980. A nomeação de "movimentos atuais" que permitirmo-nos realizar refere-se ao fato de que Lazzarato estende suas falas sobre o movimento da década de 1986 para as tensões que ele entende permearem e atravessarem os "novos” movimentos de luta e reivindicação.
} 
superfície da imagem. Ecos, ruídos, movimentos estáticos das figuras como propõe Gilles Deleuze (2007) para as pinturas de Francis Bacon. Pulsações em movimentos políticos. Funcionamento. Isso funciona, e como é que isso funciona? (DELEUZE, 2006, p. 16).

Cinema-ficção que inventa o mundo fluidificando-o, espalhando-o, maquinando-o. Talvez não seja possível diferenciar a ficção da realidade e a realidade do ficcional. Nem a realidade da imaginação. Nem o concreto do fluído. Lutas de movimentos. Reivindicação de pensamento. Nem... nem... cenas $^{678}$, cenários, cacetetes. Classificações limpadas, varridas e amassadas no deslize por entre perturbações de cinema ao invadir os jornais, os telefones celulares, as resistências.
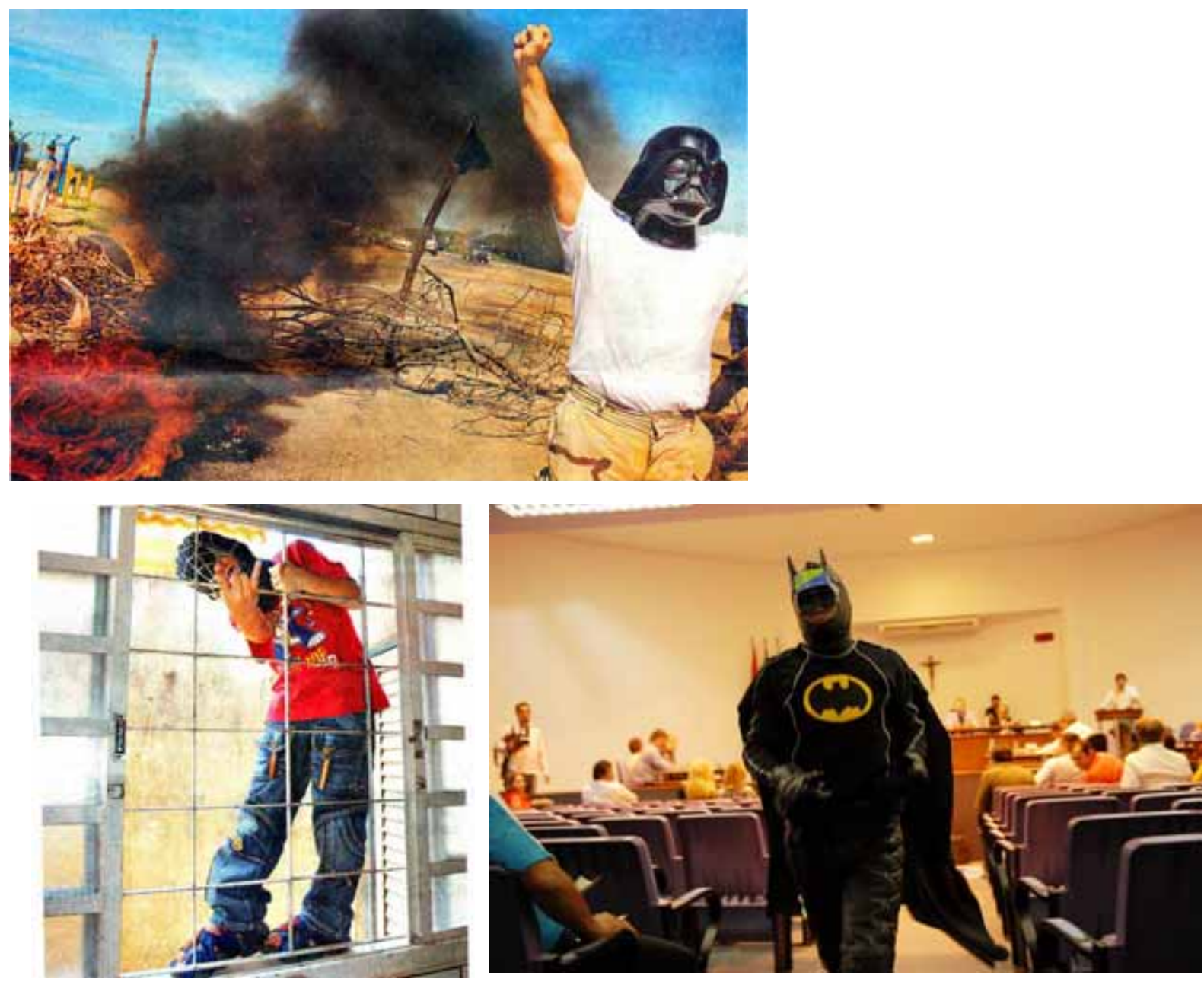

\footnotetext{
${ }^{6}$ Crédito da fotografia: Dado Galdieri/Associated Press. Foto da esquerda - Manifestante com máscara de Darth Vader grita slogans diante de barreira em Santa Cruz de la Sierra durante greve contra Evo Morales (Folha de São Paulo, capa de 29 de novembro de 2007).

${ }^{7}$ Crédito da fotografia: Tiago Brandão/”Comérico da Franca”. Foto da direita - Com roupa de Homem Aranha, garoto de 4 anos salva irmã de afogamento (Folha de São Paulo, p. D1 de 05 de janeiro de 2008).

${ }^{8}$ Homem fantasiado de Batman invade a Câmara dos Vereadores da cidade de Joinville (SC) durante sessão em que os legisladores municipais aprovaram um aumento de $36 \%$ nos seus salários. Crédito da fotografia: Salmo Duarte/Agência RBS/AE. Fonte: http://noticias.uol.com.br/album/080605_album.jhtm?abrefoto=35 . Visitado em 05/06/2008
} 


\begin{abstract}
Um desvio é pensar na profundidade da superfície em que as imagens (desenhos animados) se colocam sobre as imagens (tempo, duração, movimento) em constantes pulsações. O resultado é uma distorção da imagem, uma distorção que decompõe o plano simétrico que organizou corpos e objetos e os representa como sendo ou não passíveis de identificação (AMORIM, p. 186, 2006).
\end{abstract}

Desvios e perturbações de cinema com vilões e super-heróis que agora povoam as manchetes dos jornais fora do caderno de “cultura”. “(...) Agarrar o mundo para fazê-lo fugir, em vez de expulsá-lo ou acariciá-lo” (DELEUZE; GUATTARI, 1977: 89). Darth Vader contra Evo Morales. Homem-Gustavo-Aranha salvando sua irmã de um afogamento. Batman revoltado contra o auto-aumento proposto pelos vereadores. Flexibilidade em transitar por entre fronteiras de máscaras, resistências, fotografias em meios de comunicação; plasticidade no embaçamento cinema-HQ-fotografia, e reversibilidade do tirar e colocar as máscaras. Singularidades desejantes que teimam em pular da tela, em agarrar o mundo e se instalar numa greve, num afogamento e num protesto. Expulso-espalhado-espelhando-espalhando-se. Outras (im)posssibilidades para os movimentos políticos de resistência às fixações, classificações, significações, explicações.

Cinema que inventa, que cria, que fabula. Cinema que, com Deleuze, não precisa mais ser pensado como reflexo ou reflexão da realidade, mas como uma possibilidade em (?) levar o pensamento àquilo que a representação não comporta (FURTADO, 2007, p.101): aos extremos, à radicalidade, aos limites. Desvia o pensamento para a não necessidade de justificativas e de explicações, para a impossibilidade de comparações e significações. Na expulsão da busca pela equivalência representacional, desfazer-se, deslocar o "se” (self). "O que isso significa”? “Isso”. “Mas, o que isso significa?” “Aquilo”. “Aquilo significa o quê?” círculos concêntricos de significação e representações que parecem movimentar-se organicamente, organizadamente. Propomos pensamentos em séries disjuntivas que não pretendem centrar, nem narrar, nem organizar, mas desejar na potência do maquínico. Pensamentos com o cinema às voltas com acontecimentos, infinitude de múltiplos (FURTADO, 2007), multidão.

Máscaras de cinema a pular pelo mundo, devir-cinema nas máscaras que não são mais nem o vilão de Star Wars, nem os heróis das HQs, nem cinema. Multidão e multiplicidades na limpeza e na nitidez que coagulam sentidos, intensificam forças na indiscernibilidade do entre. Arraste do que Deleuze disse sobre as pinturas de Francis Bacon e 


\section{Área Temática: Educação Visual, Linguagens Visuais e Arte}

a deformação do que supostamente estivesse sendo figurado, narrado, propondo que o pintor irlandês tenha renegado o que o filósofo francês chama de "simples transformação" das figuras na tela (2007, p. 64). A potência das pinturas de Bacon para a lógica da sensação pensada no livro de Deleuze (2007) é o horror causado pela desmontagem da organização dos órgãos do corpo (em organismo). Não transformar, o que ainda asseguraria a narrativa, a representação, a busca pela forma "ideal”, mas deformar, que seria sempre do corpo. "Ela [a deformação] é estática, ocorre sempre no próprio lugar e subordina o movimento à força,” (...).

Quando uma força se exerce sobre uma parte que foi limpada, ela não dá origem a uma forma abstrata, assim como não combina dinamicamente formas sensíveis: ao contrário, ela faz dessa uma zona de indiscernibilidade comum a várias formas, irredutíveis a qualquer uma delas, e as linhas de força que ela faz passar escapam de toda forma por sua própria nitidez, por sua precisão deformante (DELEUZE, 2007, p. 64-65).

O funcionamento de uma pintura que se descola do organismo para ressoar em ritmos maquínicos. Potência das forças muito além do conteúdo, libertadas do conteúdo. Roubar essa idéia para pensar em derrubar os adjetivos paralisantes de protestador para o Darth Vader e Batman e de salvador para o pequeno Homem Aranha. Limpar idéias préfixadas para que a força seja intensiva. Extensiva às fotografias em que nos aparecem tais potências. Máscaras que não contam histórias, não narram, não figuram, mas acúmulo de sensações em forças invisíveis. Multidões de provocações, potência em vida, em movimento, em arrastes, em lutas, em imagens de celulares, em telas inexistentes ${ }^{9}$ que existem, subsistem, insistem numa indefinição de fronteiras classificatórias. Alô! Alô! Marciano, de que T(t)erra falamos? Que(m) fala? “(...) Insistência de um grito que subsiste à boca, insistência de um corpo que subsiste ao organismo,” (...) (DELEUZE, 2007, p. 57). Excesso de presença. Presença interminável. Máquina-máscara-devir funcionamento como nos propõe Antonio Carlos Amorim ao ressoar as discussões de Deleuze com as pinturas de Francis Bacon e as

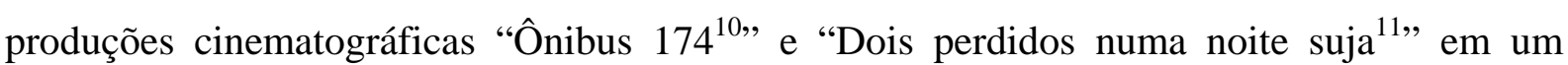
pensamento sobre educação.

\footnotetext{
${ }^{9}$ A empresa alemã Carl Zeiss mostra nesta edição da CeBIT (Feira de Tecnologia ocorrida de 04 a 09 de março de 2008 em Hanover, Alemanha, contando com 5845 expositores de 77 países. Fonte: http://www1.folha.uol.com.br/folha/informatica/ult124u378014.shtml - visitado em 12/05/2008) o "Cinemizer", um par de óculos que, conectado a um iPod, cria uma "tela imaginária" na qual o usuário pode assistir a filmes que são projetados nesta tela que tem $115 \mathrm{~cm}$ (na diagonal), a uma distância de $2 \mathrm{~m}$, num tamanho que é "sentido" pelos olhos do usuário; http://tecnologia.terra.com.br/interna/0,,OI2655748-EI11385,00.html visitado em 31/03/2008.

${ }^{10}$ Produção nacional com direção de José Padilha, 2002.

${ }^{11}$ Produção nacional, com direção de José Joffily, 2003.
} 


\begin{abstract}
Os interesses em explorar as potencialidades das imagens como pensamento para a educação passeiam com fotografias e com imagens de cinema ${ }^{12}$. Em ambas as situações, o desejo é o mesmo do cenário da inutilidade, de pretender ao não-senso, à insignificância, à banalidade, ou até mesmo ao desaparecimento e à ausência. Em especial, este tipo de pensamento desconstrói a narrativa e a centralidade nas identidades. "A expectativa é que não houvesse mais rosto, não houvesse mais olhar, não houvesse mais corpo - órgãos sem corpo, fluxos, moléculas de fractal” (Jean Baudrillard, s/d) ) (AMORIM, 2006, p. 1369).
\end{abstract}

O mesmo desejo da inutilidade, do desaparecimento do rosto ao depararmo-nos com a fabulação de mundos que continuamos a ver movimentar por entre as imagensmáquinas que aqui trouxemos para esse texto. Substância de expressão expandida para além e aquém da relação linear significante-significado e, acompanhadas de Guattari (2000), perambular por domínios extra lingüísticos do que comumente se define como Conteúdo e Expressão deslizando por domínios não-humanos (humano no sentido de orgânico, de organização de órgãos e significados). Lutas e resistências políticas na dispersão, na produção de sentidos em linhas de fuga para pensamentos da contemporaneidade, na proliferação dos movimentos de seres, pessoas, personagens, objetos, de vida, enfim.

\title{
REFERÊNCIAS
}

AGAMBEN, G. Defining movement. Seminário realizado em Padova na Nomad University com o tema Guerra e Democracia, em janeiro de 2005. Transcrito e traduzido por Arianna Bove. Disponível em: http://www.generation-online.org/t/translations.htm . Acesso em: jun. 2008.

AMORIM, A. C. R. Invisível e não enunciável: cinema brasileiro e amnésia de identidades. Educação \& Sociedade, v. 27, n.97, p. 1367-1372, set./dez., 2006.

DELEUZE, G.; GUATTARI, F. Kafka, por uma literatura menor. Rio de Janeiro: Imago, 1977.

. Lógica do sentido. 4.ed., 2.reimpressão. São Paulo: Editora Perspectiva, 2003.

Francis Bacon: lógica da sensação. Rio de Janeiro: Jorge Zahar Editor, 2007.

\footnotetext{
${ }^{12}$ Aproximações com o projeto de pesquisa "Escritascurrículo, diferenças em acontecimentos", financiado pelo CNPq (Proc. n. 401356/2006-0), no qual o campo do currículo tem interface com os estudos de cinema, vídeo, arte e museografia.
} 
FURTADO, S. B. B. Imagens que resistem. O intensivo no cinema de Aleksander Sokurov. 2007. Tese (Doutorado) - Departamento de Ciências Sociais, Universidade Federal do Ceará, 2007.

GUATTARI, F. Caosmose: um novo paradigma estético. São Paulo: Editora 34, 2000.

LAZZARATO, M. A deafening noise. Publicado originalmente em Futur Antérieur 23, 1994/3-4. Tradução disponível em: http://www.generation-online.org/t/translations.htm. Acesso em: jun. 2008.

VIRNO, P. One and many. Em italiano: Quando il verbo si fa carne (Bollati Boringhieri, Torino, 2003) Traduzido para o inglês por Nate Holdren. Capítulo 7, p.186-187. Disponível em: http//www.generation-online.org/t/translations.htm . Acesso em jun. 2008.

ELENISE CRISTINA PIRES DE ANDRADE

É Bióloga. Mestre e doutora em Educação pela Faculdade de Educação da UNICAMP. Professora e coordenadora do curso de Pedagogia das

Faculdades Network.

ÉRICA SPEGLICH

É bióloga, Mestre em Educação e Doutoranda do Programa de PósGraduação em Educação da Unicamp. Bolsista CNPq. 